\title{
Infección de vías urinarias no complicada en mujeres
}

\section{Uncomplicated urinary tract infections in women}

\author{
Ana María Becerra ${ }^{1}$ Daniel Parra ${ }^{1}$ Carlos Gustavo Trujillo ${ }^{1} \quad$ Julián Azuero $^{1}$ Sandra García ${ }^{1}$ \\ Fabián Daza ${ }^{1}$ Mauricio Plata1잉
}

\author{
${ }^{1}$ Departamento de Urología, Hospital Universitario Fundación Santa \\ Fe de Bogotá, Facultad de Medicina, Universidad de Los Andes, \\ Bogotá, Colombia
}

Address for correspondence Mauricio Plata, MD, Hospital Universitario Fundación Santa Fe de Bogotá, Bogotá, Colombia (e-mail: mauricio.plata@fsfb.org.co).

Urol Colomb 2021;30:123-134.

\section{Resumen \\ Palabras clave \\ - infección \\ - tracto urinario \\ - cistitis no complicada \\ - resistencia \\ - prevención \\ - terapia antibiótica}

La infección de vías urinarias (IVU) es una patología común, que afecta a gran parte de la población y que generalmente se resuelve con manejo de antibiótico. Se compone de una amplia variedad de entidades clínicas que pueden variar desde una cistitis no complicada hasta un shock séptico de origen urinario. Los patógenos etiológicos de la IVU no complicada están ampliamente establecidos y se han mantenido de forma consistente a lo largo del tiempo, siendo la Escherichia coli el microorganismo más predominante. En la actualidad, la resistencia bacteriana a los antibióticos es de gran preocupación y por esa razón, se busca optimizar la terapia antimicrobiana con el fin de disminuir la estancia hospitalaria, la severidad clínica de la infección y los costos a los sistemas de salud. La presente revisión, tiene como objetivo servir como guía para la correcta definición, clasificación, diagnóstico, tratamiento y prevención de la IVU no complicada.

A urinary tract infection (UTI) is a common pathology, that affects a large part of the population and generally resolves with antibiotic treatment. It embraces a variety of clinical entities that can vary from uncomplicated cystitis to septic shock. The etiological pathogens of uncomplicated UTI are widely established and have been consistent over time, with Escherichia coli being the most predominant microorganism. Currently, bacterial resistance to antibiotics is of great concern and for this reason we seek to optimize antimicrobial therapy in order to decrease hospital stay, clinical severity of the infection and costs to the health systems. The purpose of this review is to serve as a guide for the correct definition, classification, diagnosis, treatment and prevention of uncomplicated UTI.

\section{Introducción}

La infección de vías urinarias (IVU) es una patología común, principalmente de origen bacteriano, que afecta a gran parte de la población y que generalmente se resuelve con manejo antibiótico. Se compone de una amplia variedad de entidades clínicas que pueden variar desde una cistitis no complicada hasta un shock séptico de origen urinario. ${ }^{1}$ Al día de hoy, es la received

July 20,2020

accepted

September 1, 2020

published online

February 4, 2021
DOI https://doi.org/

$10.1055 / \mathrm{s}-0040-1721323$

ISSN 0120-789X.

e ISSN 2027-0119.

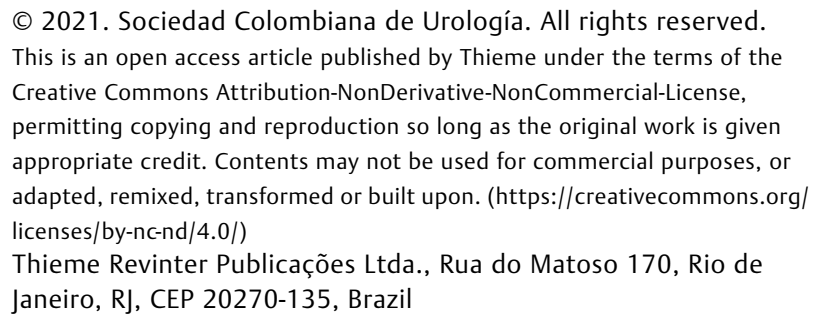

(C) 2021. Sociedad Colombiana de Urología. All rights reserved. This is an open access article published by Thieme under the terms of the Creative Commons Attribution-NonDerivative-NonCommercial-License, permitting copying and reproduction so long as the original work is given appropriate credit. Contents may not be used for commercial purposes, or adapted, remixed, transformed or built upon. (https://creativecommons.org/ licenses/by-nc-nd/4.0/)

Thieme Revinter Publicações Ltda., Rua do Matoso 170, Rio de Janeiro, RJ, CEP 20270-135, Brazil 
infección bacteriana más común adquirida en la comunidad, siendo el $80 \%$ de pacientes afectados del sexo femenino. ${ }^{2,3}$

Cada año en el mundo, se estima que 7 millones de mujeres consultan al servicio de salud por una IVU, resultando en más de 100,000 hospitalizaciones. ${ }^{1,4}$ En la actualidad, la resistencia bacteriana a los antibióticos es de gran preocupación y por esa razón, se busca optimizar la terapia antimicrobiana con el fin de disminuir la estancia hospitalaria, la severidad clínica de la infección y los costos que alcanzan hasta los 20 billones de dólares al año en países como Estados Unidos. ${ }^{5}$ La presente revisión, tiene como objetivo servir como guía para la correcta definición, clasificación, diagnóstico, tratamiento y prevención de la IVU no complicada.

\section{Definiciones y clasificación}

La infección urinaria puede definirse como la manifestación clínica a una respuesta inflamatoria del urotelio generalmente secundaria a la invasión bacteriana. ${ }^{1,6}$ Se puede clasificar según la localización, el estado funcional o anatómico y la severidad como se representa en la - Figura 1.

IVU no complicada: Infección urinaria del tracto urinario inferior o superior en pacientes de sexo femenino premenopáusicas, que no presentan ninguna de las siguientes características: estado gestacional, instrumentación del tracto urinario ni alteraciones anatómicas o funcionales. ${ }^{6-8}$

IVU recurrente: Se define como 2 episodios de IVU no complicada y/o complicada en 6 meses o la presencia de 3 o más episodios en 12 meses; con la condición de que haya habido una resolución completa de la clínica entre cada episodio. ${ }^{7,9}$ Para el diagnóstico es necesario tener aislamiento de los patógenos en urocultivos. Clasificación por patogénesis de la IVU recurrente ${ }^{3,9,10}$ :

- Persistencia bacteriana: se debe a la persistencia de un foco de infección por el mismo agente patógeno, que puede deberse a una concentración subterapéutica del antibiótico, incumplimiento del esquema de tratamiento, trastornos de malabsorción o la presencia de patógenos resistentes. Además, no se obtiene un urocultivo negativo posterior al tratamiento y persiste la sintomatología.

- Reinfección: se presenta como un nuevo evento de infección urinaria por el mismo germen o uno diferente que es adquirido a partir de la flora periuretral, perineal o rectal tras una resolución completa de la clínica del episodio anterior o un urocultivo negativo.

Cistitis o infección urinaria baja: Se caracteriza por síntomas urinarios irritativos como disuria con o sin aumento de frecuencia, urgencia, tenesmo vesical, dolor suprapúbico o hematuria; generalmente en ausencia de secreción e irritación vaginal. ${ }^{3,7}$

Pielonefritis o infección urinaria alta: Se caracteriza clínicamente por la presencia de dolor en el flanco, náuseas, vómito, fiebre mayor a $38^{\circ} \mathrm{C}$ o hipersensibilidad en el ángulo costovertebral ipsilateral, que puede ocurrir en ausencia o presencia de síntomas de cistitis. ${ }^{3}$ Se puede clasificar en pielonefritis obstructiva o no obstructiva según la presencia o no de hidronefrosis.

A continuación, se presentan otras definiciones que son de importancia para tener en cuenta cuando se estudia una infección urinaria.

Bacteriuria asintomática: Se define como la invasión bacteriana en el tracto urinario en ausencia de sintomatología $\mathrm{y}$ en presencia de un recuento $\geq 10^{5} \mathrm{UFC} / \mathrm{ml}$ de un microorganismo en dos muestras de orina consecutivas en mujeres y una única muestra en hombres. ${ }^{3,7,11}$ En el caso de que se haya usado sonda para la toma de la muestra un recuento $\geq 10^{2} \mathrm{UFC} / \mathrm{ml}$ es suficiente para el diagnóstico. ${ }^{3}$ Requiere tratamiento sólo en casos seleccionados como mujeres embarazadas y en pacientes en quienes se realizará instrumentación del tracto urinario. 3,7,11,12

IVU asociada a catéter: Se presenta en pacientes cuya vía urinaria es cateterizada de manera recurrente o lo ha sido en las últimas 48 horas. $^{7}$ Se define por la presencia de síntomas o signos compatibles con infección urinaria sin otra causa identificable y un urocultivo de más de $10^{3} \mathrm{UFC} / \mathrm{ml}^{3}$

IVU complicada: Se define como IVU que se presenta en pacientes con alteraciones anatómicas $\mathrm{y} / \mathrm{o}$ funcionales

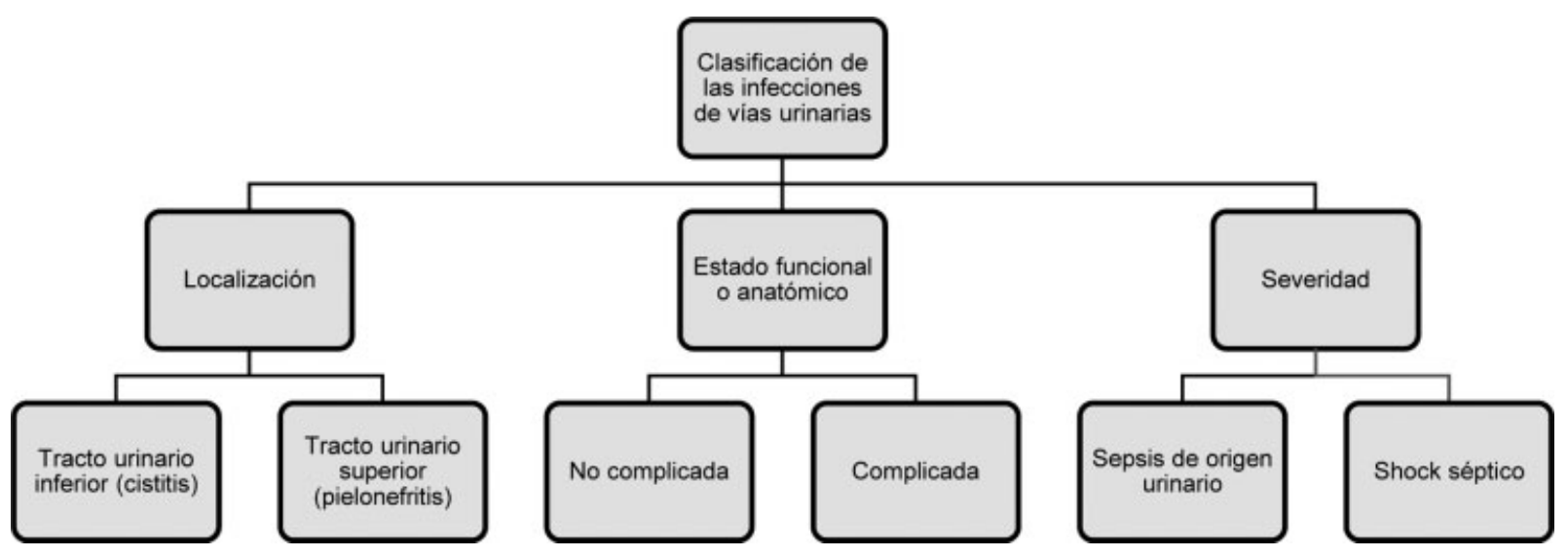

Fig. 1 Clasificación de infecciones de vías urinarias. 
relevantes del tracto urinario. ${ }^{7}$ Incluye también infecciones en hombres, niños, inmunosuprimidos, diabéticos, asociadas a catéteres de la vía urinaria, a obstrucción, pacientes con insuficiencia renal, trasplante renal, neurogénicos, entre otros. ${ }^{7}$

Urosepsis o sepsis de origen urinario: Es una disfunción orgánica que amenaza la vida causada por una respuesta no regulada del huésped ante una infección cuyo foco se encuentra en el tracto urinario, confirmado por métodos microbiológicos o criterios clínicos. ${ }^{13}$ Dentro de los criterios para el diagnóstico de disfunción orgánica se describen 3 herramientas, la escala SOFA (Sequential Organ Failure Assessment), su versión abreviada denominada qSOFA y SIRS (síndrome de respuesta inflamatoria sistémica). ${ }^{14-16}$ La escala SOFA tiene una mayor validez predictiva para mortalidad intrahospitalaria en UCI, asociándose un puntaje $\geq 2$ con un riesgo de $10 \%$ para mortalidad intrahospitalaria, aumentando el riesgo 2-25 veces más al compararse con un puntaje $<2 .^{15,16}$ El SIRS por sí solo, se define como el compromiso del estado general acompañado de signos de respuesta inflamatoria sistémica, que frente a una clara infección del tracto urinario se denomina sepsis de origen urinario.

\section{IVU baja no complicada: Frecuencia de la enfermedad y} factores de riesgo potenciales

Se considera que el $60 \%$ de las mujeres, el grupo poblacional más afectado, presentarán por lo menos un episodio de cistitis aguda a lo largo de su vida y que un $25-50 \%$ de ellas experimentarán una recurrencia. ${ }^{7,17}$ La incidencia anual es de aproximadamente $12,1 \%-18,6 \%$ con un pico entre los $20-24$ años. ${ }^{4}$ En mujeres sanas en edad reproductiva, la prevalencia es entre $1-5 \%$ pero asciende a un $2-10 \%$ en aquellas en estado de embarazo. ${ }^{7,18}$ En mujeres postmenopáusicas la prevalencia es del 4-19\%. ${ }^{7,18}$

Aunque los datos de prevalencia de IVU en Colombia son limitados, un estudio realizado en la ciudad de Medellín reportó una prevalencia del 31\% en 1959 pacientes atendidos en una institución prestadora de servicios de salud (IPS) de tercer nivel. El anterior hallazgo es concordante con un estudio en la ciudad de Cartagena que reporta una prevalencia del $28 \%{ }^{18,19}$

Dentro de los principales factores de riesgo, la vida sexual juega un papel importante. ${ }^{20}$ Scholes y col., demostraron en un estudio de casos y controles, que la frecuencia de relaciones sexuales y la presencia de nuevas parejas impacta en el desarrollo de infecciones urinarias y, que las mujeres que no tienen vida sexual activa tienen un menor riesgo de desarrollarlas. ${ }^{21}$

Otro potencial factor de riesgo modificable implica la alteración de la flora vaginal y eventualmente el cambio del pH vaginal con alteración del lactobacilo. Eso puede ocurrir con el uso de anticonceptivos de barrera y es la razón por la cual existe una asociación entre el desarrollo de IVU y el uso de espermicidas y condones que los contienen. ${ }^{21}$

Desde el punto de vista anatómico, la presencia de prolapso genital e incontinencia urinaria se han asociado con el desarrollo de IVU. Al parecer, la alteración de la flora vaginal por la presencia de orina y los cambios en la piel genital por dermatitis amoniacal son factores de riesgo. El prolapso genital, especialmente el de alto grado que se asocia a la obstrucción del tracto urinario, puede ser un factor de riesgo modificable. ${ }^{22}$ Por último, la atrofia genital que ocurre con el síndrome urogenital de la menopausia y que se abordará más adelante, también aumenta el riesgo.

\section{Patogénesis}

La metagenómica, definida como el estudio del material genético que es obtenido directamente de muestras ambientales, ha permitido entender la patogénesis de la infección de vías urinarias extrapolada de modelos animales. ${ }^{23}$ Los uropatógenos deben adherirse, colonizar, adaptarse al ambiente de la vejiga, evadir el sistema inmune del huésped, persistir y diseminarse por el tracto urinario. ${ }^{24}$ El primer paso, es el ascenso de las bacterias por la uretra y su adherencia a la capa superficial del urotelio, específicamente a las células en sombrilla, utilizando unos filamentos adhesivos llamados pili. Se han identificado al menos 38 tipos de pili en el uropatógeno E. coli, algunos de los cuales presentan tropismo ya sea por el epitelio del tracto urinario inferior (cistitis) o del superior (pielonefritis). ${ }^{24} \mathrm{Sin}$ embargo, son las interacciones entre el patógeno y el huésped las que determinarán si hay una colonización exitosa o si son eliminados por el sistema inmune. ${ }^{25}$ Posterior a ese evento, las células bacterianas son internalizadas donde encuentran un ambiente ideal para el crecimiento y la formación de comunidades intracelulares bacterianas (CIB). ${ }^{23}$

Como respuesta a ese fenómeno, se produce una cascada de eventos locales que involucran la liberación de sustancias como el factor de crecimiento tumoral, interleucina 6 , interleucina 7 y ligandos específicos para quimiocinas. ${ }^{26}$ Todo eso desencadena la liberación tanto de neutrófilos a nivel del urotelio, como de monocitos que buscan reducir el número de bacterias, pero exponen por exfoliación al urotelio. ${ }^{26}$ Esa exposición genera a su vez, la adherencia de bacterias al urotelio formando reservorios intracelulares quiescentes y que pueden ser los responsables de persistencia de infección o IVU recurrente. ${ }^{27}$ De hecho, se ha visto que en cistitis crónica inducida en ratones, la expresión de factores como el de necrosis tumoral es mucho más temprana, sirviendo como un potencial marcador en el futuro para pacientes con IVU recurrente, al igual que la expresión de ciclooxigenasa $2 .^{28}$

El cambio o alteración de la flora vaginal normal es también un potencial factor asociado. Se ha evidenciado cómo la infección vaginal por ciertos patógenos puede favorecer la infección urinaria al facilitar la activación de E. coli latente. ${ }^{25}$ Además, ciertas bacterias vaginales se han asociado inclusive a una mayor exfoliación del urotelio.

Otra vía potencial de generación de virulencia de las enterobacterias, es la expresión de pilis de la vía Chaperon-Usher. ${ }^{25}$ El E. Coli uropatógeno, expresa 12 sitios que median cada uno por separado, la unión a receptores específicos en superficies celulares. Son 4 los pili de la vía Chaperon-Uscher que están comprometidos en el desarrollo de la IVU. El pili tipo 1, el pili P, el pili UCL o F17 y el pili FML. ${ }^{25}$ 
El primero se fija a uroplaquinas del epitelio del tracto urinario a través de componentes manosilados, y el segundo se fija a glicanos en el tracto gastrointestinal actuando como reservorio. ${ }^{25}$ Los más prevalentes son los pili tipo 1, que en su extremo distal cuentan con FimH, un sitio de unión a glicoproteínas que contienen manosa como las uroplaquinas y las integrinas $\alpha 1 \beta 3$ que recubren la mayoría del epitelio vesical. ${ }^{24,29}$ El pili FML se pega a otro proteoglicano expresado en vejiga y riñones con inflamación crónica y el pili P se pega a globósidos en los riñones. Muchas bacterias gram negativas incluyendo $E$. Coli, pero también Klebsiella spp, Proteus spp y Pseudomonas spp, expresan fibras de adherencia a través de esa vía. ${ }^{30}$ La E. coli por ejemplo, al expresar lipopolisacáridos en su superficie puede ser detectado por el TLR4 (toll-like receptor 4, por sus siglas en inglés), una proteína de membrana que induce producción de AMP cíclico y un fenómeno de exocitosis bacteriana que puede ser revertida por la $E$. Coli volviendo al citoplasma y formando las CIB, responsables de muchas de las resistencias, persistencias y recurrencias de las IVU. ${ }^{31}$

Existen otros factores de virulencia como la producción de proteasas y toxinas que liberan nutrientes de las células del huésped para crear nichos de invasión y así promover la diseminación. ${ }^{24}$ La E. coli secreta altas concentraciones de alfa-hemolisina que tiene la capacidad de formar poros y lisar las células uroteliales, haciendo que el hierro y otros nutrientes se encuentren disponibles para los patógenos infectantes. $^{24}$ Asimismo, la E. coli cuenta con sideróforos como la yersiniabactina y salmoquelina. ${ }^{24,32,33}$ Ellos son importantes ya que una forma de defensa del huésped es el secuestro de metales a través de la expresión de lactoferrina. La bacteria se defiende a través de los sideróforos que fijan hierro y cobre en el espacio extracelular y lo internalizan para su supervivencia.

Por otro lado, el factor necrotizante citotóxico 1 se expresa en $40 \%$ de las $E$. coli uropatogénicas e ingresa a las células del huésped por vesículas endocíticas, se unen a receptores y generan cambios en el citoesqueleto, lo que aumenta los niveles de internalización bacteriana promoviendo su supervivencia. $^{24,34}$ Finalmente, cambios estructurales como la adopción de una morfología filamentosa, concede a las bacterias una mayor resistencia contra los neutrófilos en comparación con su morfología de bacilo. ${ }^{24}$

Los uropatógenos intracelulares posteriormente van a madurar hacia biofilms; que son grupos de bacterias de una única o múltiples especies encapsuladas en una matriz rica en polisacárido y rodeadas en una capa de uroplaquina, que va a permitir la persistencia y recurrencia de las IVU al crear una barrera contra mecanismos de defensa del huésped y agentes antimicrobianos. ${ }^{24,35}$ A través de canales, viajan libremente nutrientes que permiten la persistencia bacteriana en un ambiente idóneo. Los biofilms se asocian habitualmente a la infección urinaria en presencia de cuerpos extraños como catéteres.

Algunas enterobacterias tienen plásmidos que adquieren la capacidad de codificar para expresión de betalactamasas. Por ejemplo, las betalactamasas de espectro extendido confieren resistencia a cefalosporinas y otros antibióticos. $^{36}$ Otra betalactamasa expresada por enterobacterias, incluye las tipo AMPc que se asocian a la resistencia para carbapenémicos en algunas cepas de Klebsiella pneumoniae. Recientemente ha sido reportada la expresión de resistencia a glicopéptidos por el enterococo incluyendo la vancomicina; considerada última línea de defensa en esas infecciones. ${ }^{37}$

Es bien conocido, que las mujeres premenopáusicas presentan una mejor respuesta a las infecciones del tracto urinario inferior, en parte por la alta colonización de Lactobacillus spp. ${ }^{38}$ Esas bacterias producen ácido láctico a partir de la fermentación del glicógeno producido por las células epiteliales dependientes de estrógenos, manteniendo el pH ácido de la vagina, protegiendo la microbiota vaginal, previniendo las disbiosis y evitando la adherencia de uropatógenos incluido la $E$. coli que generan infección. ${ }^{39-41}$

En contraste, las mujeres postmenopáusicas presentan cambios relacionados con la disminución de los niveles hormonales tanto de andrógenos como de estrógenos. Lo anterior resulta en atrofia del epitelio vaginal, llevando a la disminución en la concentración de Lactobacillus spp y a su vez, una menor producción de ácido láctico que aumenta el pH vaginal, lo que crea un ambiente más propicio para la sobreinfección del tejido urogenital. ${ }^{39}$

\section{Microbiología}

Los patógenos etiológicos de la IVU no complicada están ampliamente establecidos y se han mantenido de forma consistente a lo largo del tiempo. La $E$. coli es el microorganismo más predominante, con una prevalencia en los distintos estudios entre el 75-95\%.,42 Especial consideración se ha de tener con la E. coli, por la presencia del pili tipo 1 que le confiere un factor de virulencia especial y una mayor colonización del tracto urinario. El segundo patógeno en prevalencia, ha sido variable en los diferentes estudios alrededor del mundo, y en algunas series, ese lugar lo ocupa Klebsiella pneumoniae o Staphylococcus saprophyticus, con prevalencias de hasta un $15 \%$ en Norteamérica, y por último Enterococcus faecalis. ${ }^{2,43}$

Aunque en Colombia no hay estudios epidemiológicos grandes, la E. coli es también el microorganismo más prevalente. En nuestra institución, el Hospital Universitario Fundación Santa Fe de Bogotá, la E. coli fue aislada en el $47 \%$ y $42 \%$ de los casos en los años 2016 y 2017 , respectivamente. ${ }^{44}$ En el 2019 se aisló en el 39\% de las muestras de pacientes hospitalizados y $60 \%$ de los ambulatorios (-Figura 2). El segundo lugar de prevalencia varía dependiendo de la región del país. En Bogotá, hay reportes de Enterococcus faecalis con un 12,3\%, mientras que en otras regiones como el eje cafetero y Cauca se observa presencia de Klebsiella pneumoniae con prevalencias de $19,2 \%$ y $8,7 \%$, respectivamente. ${ }^{44-46}$ En nuestra institución, se aisló en segundo lugar Enterococcus faecalis en 13\% de los casos y en tercer lugar Klebsiella pneumoniae en un $8 \%$ (-Figura 2), tanto en pacientes hospitalizados como en ambulatorios. Otros posibles agentes causales son Pseudomonas Aeruginosa, Proteus Mirabilis y hongos como 


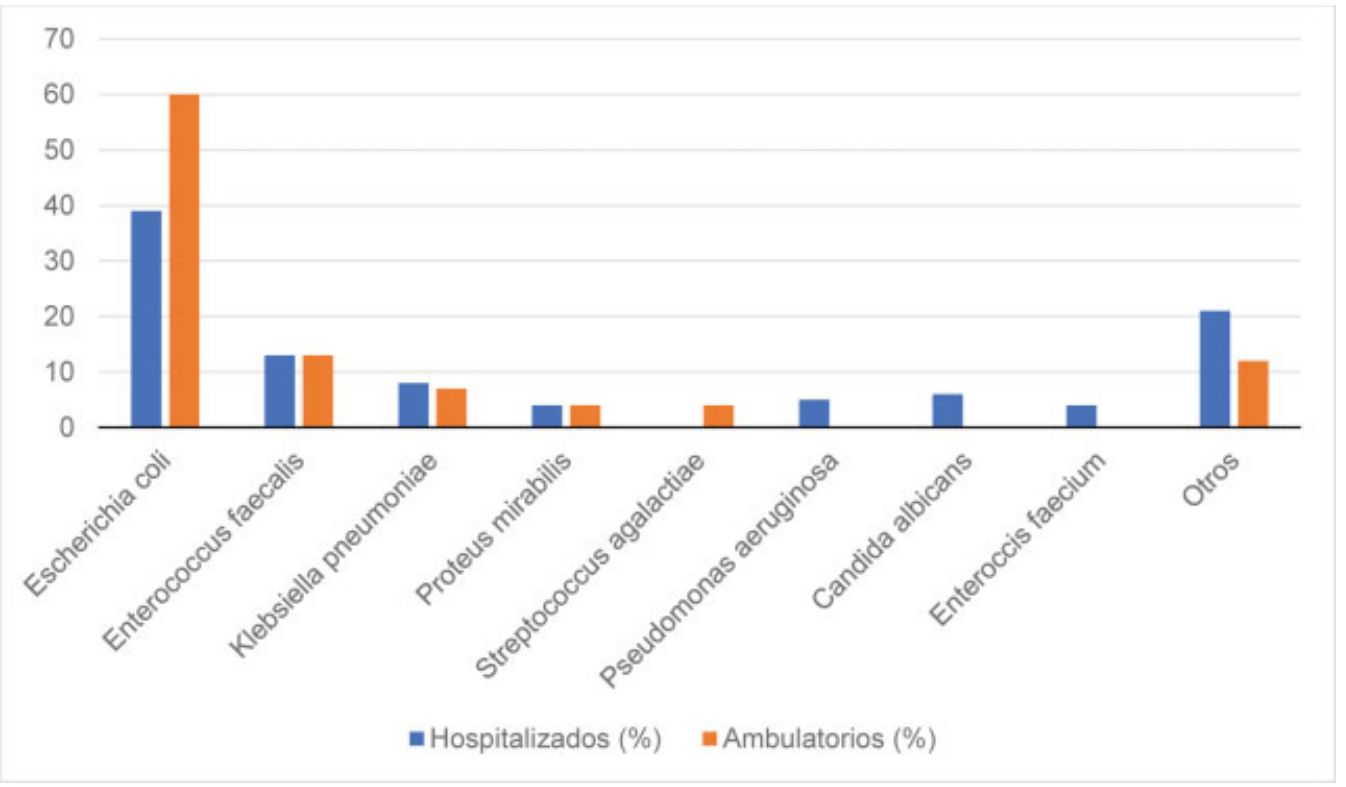

Fig. 2 Microorganismos aislados en orina en Ambulatorios y Hospitalizados en 2019.

Cándida Albicans, especialmente en pacientes hospitalizados o en cuidados intensivos. ${ }^{44}$

Otros de los microorganismos a tener en cuenta son la Chlamydia spp, que se debe sospechar en pacientes con síntomas sugestivos y urocultivo negativo, y el Mycobacterium tuberculosis que, si bien hoy en día es inusual, se ha de sospechar en pacientes con hematuria y piuria sin bacteriuria. De igual manera, debe considerarse la colonización por Cándida y el desarrollo subsecuente de la IVU en pacientes con uso prolongado de antibióticos y/o portadores de catéteres urinarios.

\section{Diagnóstico}

El diagnóstico de la IVU baja no complicada es clínico y se debe sospechar en presencia de síntomas irritativos (o de almacenamiento) del tracto urinario inferior como disuria, aumento de frecuencia, urgencia, tenesmo vesical, dolor suprapúbico y/o hematuria. ${ }^{3}$ La presencia de uno de esos síntomas da una probabilidad pretest de cistitis en mujeres del 50\% y llega a más del $90 \%$ cuando la disuria está presente en ausencia de secreción o irritación vaginal.,12 Eso es particularmente cierto en aquellas que han padecido de episodios previos.

Se debe hacer una anamnesis enfocada en identificar hábitos miccionales y factores de riesgo como actividad sexual, uso de espermicidas, tratamiento antibiótico reciente o patologías de base que predispongan a infección o puedan generar alteraciones funcionales (ej. diabetes mellitus). El examen físico debe ir orientado a descartar alteraciones estructurales, realizando particularmente un examen genital para evaluar la presencia de atrofia genital asociado al síndrome urogenital de la menopausia, o posibles infecciones vaginales, que puedan explicar los síntomas. ${ }^{9}$

Por la alta probabilidad pretest de llegar al diagnóstico en presencia de síntomas, las guías sugieren que no es necesario hacer estudios paraclínicos. El uroanálisis y urocultivo sólo se recomiendan en caso de infecciones recurrentes. ${ }^{18}$
El uroanálisis consta de dos partes. La primera se hace con la tirilla reactiva y la segunda con un examen del sedimento. La tirilla reactiva permite determinar la presencia de leucocitos mediante la reacción de la esterasa leucocitaria. Ella marcará positiva con hasta 5 leucocitos por campo, íntegros o lisados, lo que podría generar una lectura falsa positiva. Cuando se compara con el sedimento, tiene una sensibilidad y especificidad de $80 \%$ y $70 \%$, respectivamente. ${ }^{47} \mathrm{Al}$ combinarse con la prueba de nitritos, tiene un valor predictivo positivo de $80 \%$ y negativo de $98,3 \%$ para las IVU. ${ }^{47}$ Puede presentar resultados falsos positivos por contaminación de la muestra con secreción vaginal. Por otro lado, los resultados falsos negativos pueden verse en pacientes neutropénicos, muestras de orina con gran cantidad de albúmina o glucosa, o en presencia de bacterias no desdobladoras de urea. ${ }^{47}$ Entre ese grupo se encuentran la E. coli, Klebsiella spp, Enterobacter spp y Proteus spp. Algunas bacterias como las gram positivas y Pseudomonas no son productoras de nitritos. ${ }^{48}$ Es importante anotar que la reacción requiere tiempo, por lo que un falso negativo de la prueba de nitritos puede ser secundaria a la orina que no fue almacenada en la vejiga por un tiempo suficiente. Es esa una de las bases para que tradicionalmente se sugiera tomar la muestra de la primera micción de la mañana, cuando se supone que la orina ha permanecido en la vejiga durante toda la noche.

El análisis de sedimento urinario se basa en el hallazgo de leucocitos y bacterias. Se considera normal tener de 0-4 leucocitos por campo de alto poder. Hay que recordar que su presencia puede deberse no solo a la infección, sino a la contaminación de la muestra con secreción vaginal (mala toma de la muestra), presencia de tumores $\mathrm{u}$ otras condiciones inflamatorias agudas o crónicas del tracto urinario. En cuanto a las bacterias, la presencia de 5 o más, suele ser reflejo de existencia de 100,000 unidades formadoras de colonias por mililitro. Hay que analizar ese hallazgo en combinación con otros del uroanálisis, para 
descartar contaminación de la muestra como un falso positivo. Es importante tener en cuenta que la presencia de leucocitos o piuria más bacteriuria en el sedimento urinario es lo más sensible y específico para ayudarnos en el diagnóstico de IVU. ${ }^{49}$

Además de las pruebas mencionadas, hay algunas pruebas bioquímicas, útiles para la identificación de bacterias como la tinción Gram y la prueba de oxidasa y catalasa. La tinción de Gram es una técnica que emplea colorantes que reaccionan con diferentes tipos de bacterias basado en la estructura de su pared celular; permitiendo una aproximación a la diferenciación bacteriana. ${ }^{48}$ La prueba de oxidasa está basada en la identificación de la citocromo C oxidasa; para esa prueba se utiliza el reactivo de Kovacs que al tener contacto con la citocromo $\mathrm{C}$ oxidasa cambia a un color morado. ${ }^{50}$ El resultado positivo es diagnóstico de Pseudomonas spp, Aeromonas spp o Neisseria spp. ${ }^{50,51}$ La prueba de catalasa se basa en la identificación de esa enzima en las bacterias obteniendo agua y oxígeno. El reactivo utilizado es el peróxido de Hidrógeno al 30\% que tras el contacto con la bacteria produce burbujeo intenso (oxígeno). Si sucede, su resultado positivo es diagnóstico de Staphylococcus aureus. ${ }^{50,51}$ Otra prueba utilizada es la de oxidación y fermentación, conocida como OF. Las bacterias pueden utilizar los carbohidratos por vía oxidativa, y por tanto ser aerobios, o por el contrario por el metabolismo fermentativo, que no necesita oxígeno y por tanto ser anaerobios. ${ }^{50}$ Para la prueba, se utilizan 2 tubos con agar OF y se inocula con bacterias. En un tubo se cerrará la tapa de tal forma que permita el ingreso de oxígeno, y en el otro tubo se dejará bien cerrada para incubar durante 24 horas. $^{50}$ Un positivo oxidativo (no fermentador) es Pseudomonas aeruginosa y positivo fermentador es $E$. coli (ver - Tabla 1). ${ }^{50}$

El urocultivo confirma la presencia de bacteriuria y el perfil de sensibilidad antibiótico del uropatógeno; se recomienda únicamente en aquellos pacientes con síntomas atípicos, mujeres embarazadas, sospecha de pielonefritis, uso de esquema antibiótico en los 6 meses previos o falla a un adecuado tratamiento antimicrobiano. ${ }^{7,52}$ Aunque las guías no lo consideran un examen de primera línea, ante el aumento de la resistencia bacteriana a antibióticos de uso común, consideramos prudente la toma del mismo, particularmente en pacientes con infecciones recurrentes para ajustar el tratamiento.

Las imágenes diagnósticas no hacen parte del estudio de mujeres con IVU baja no complicada. Sin embargo, en algunas series se considera la pielonefritis no obstructiva, como una IVU no complicada, aunque requiera una mayor duración de tratamiento. La infección del tracto urinario superior se puede manifestar con fiebre mayor a $38^{\circ} \mathrm{C}$, escalofríos, dolor en el flanco, sensibilidad en ángulo costovertebral, náuseas o vómito, y cursar o no con síntomas de cistitis, siendo la sensibilidad a la palpación en el ángulo costovertebral el único hallazgo en el examen físico que aumenta la probabilidad diagnóstica. ${ }^{3}$ En ese escenario, se hace necesario realizar una ecografía de vías urinarias como enfoque inicial, buscando descartar hidronefrosis. Su alta disponibilidad y seguridad al no requerir radiación ionizante, además de una alta sensibilidad para detectar dilatación, la hacen un estudio ideal. La tomografía simple o uroTAC se realizará en casos en los que se sospeche litiasis como etiología del episodio de infección. Estudios con contraste de las vías urinarias no tienen indicación durante un proceso agudo y su realización se reservará para casos seleccionados luego de tratada la infección. Finalmente, la cistoscopia no es un estudio indicado en esta patología.

\section{Tratamiento}

La IVU baja no complicada tiene un impacto importante en la calidad de vida, lo que hace que los pacientes consulten a los servicios médicos de manera frecuente. La prevención y el tratamiento son muy importantes. Esta entidad es de fácil curación y el tratamiento antibiótico adecuado se asocia con altas tasas de remisión y con disminución en la tasa de reinfección. ${ }^{53}$ Desafortunadamente, estamos enfrentados a un uso de antibióticos de manera indiscriminada, incluso en ausencia de infección. Por otro lado, existe una tendencia a la

Tabla 1 Características bioquímicas de bacilos Gram negativos y cocos Gram positivos

\begin{tabular}{|c|c|c|c|c|}
\hline \multicolumn{5}{|l|}{ BACILO GRAM NEGATIVO } \\
\hline \multirow{3}{*}{$\begin{array}{l}\text { Aerobio } \\
\text { ¿Fermentador de la lactosa? }\end{array}$} & Sí & \multicolumn{3}{|c|}{ E. coli, Klebsiella, Enterobacter } \\
\hline & \multirow[t]{2}{*}{ No } & Oxidasa $(+)$ & \multicolumn{2}{|c|}{ Pseudomonas, Aeromonas, Achomonobacter } \\
\hline & & Oxidasa (-) & \multicolumn{2}{|c|}{ Proteus, Yersinia, Acinetobacter, Serratia, Citrobacter, Salmonella, Shigella, } \\
\hline \multicolumn{5}{|l|}{ COCO GRAM POSITIVO } \\
\hline \multirow[t]{5}{*}{ Aerobio ¿Es catalasa $(+) ?$} & \multirow[t]{2}{*}{ Sí } & \multirow[t]{2}{*}{ Estafilococos } & Coagulasa $(+)$ & S. aureus \\
\hline & & & Coagulasa (-) & S. epidermidis, S. haemolyticus, S. saprophyticus \\
\hline & \multirow[t]{3}{*}{ No } & \multirow[t]{3}{*}{ Estreptococos } & Hemólisis $\alpha$ (parcial) & S. pneumoniae \\
\hline & & & $\begin{array}{l}\text { Hemólisis } \beta \\
\text { (completa) }\end{array}$ & S. agalactiae, S. pyogenes \\
\hline & & & $\begin{array}{l}\text { Hemólisis y } \\
\text { (no hemólisis) }\end{array}$ & E. faecium, E. faecalis \\
\hline
\end{tabular}


automedicación. Esa toma recurrente de antibióticos, altera la flora intestinal y/o vaginal llevando a otras patologías secundarias, asociándose también, a un aumento en la resistencia. ${ }^{54}$

En general el inicio del tratamiento antibiótico es empírico, favoreciendo un alivio rápido de los síntomas y la disminución en los cambios inflamatorios. Cuando se ha decidido solicitar uroanálisis y urocultivo, se determinará si el manejo inicial es adecuado frente al patógeno etiológico aislado. Debido a la alta tasa de resistencia bacteriana a la terapia antimicrobiana, se requiere que cada institución conozca la prevalencia de los uropatógenos y su perfil de sensibilidad al manejo antibiótico. La duración del tratamiento debe ser tan corta como sea razonable, generalmente no mayor a 7 días. ${ }^{17}$ La Asociación Europea de Urología (EAU por sus siglas en inglés), sugiere como tratamiento inicial el uso de nitrofurantoina y fosfomicina, con un nivel de evidencia fuerte y estima que se debe evitar el uso de amino penicilinas y fluoroquinolonas en infecciones bajas no complicadas. ${ }^{7,55}$ Aunque la fosfomicina es una alternativa de primera línea, recomendamos evitar su uso, ya que ha demostrado ser útil en el manejo de Klebsiella pneumoniae carbapenemasa (KPC), para la cual no existiría alternativa diferente a la colistina, con sus efectos adversos conocidos. ${ }^{56} \mathrm{El}$ esquema inicial recomendado para cistitis no complicada es:

- Nitrofurantoina macrocristales $100 \mathrm{mg}$ cada 6 a 8 horas por 5 a 7 días.

- Nitrofurantoina liberación prolongada $100 \mathrm{mg}$ cada 12 horas por 5 a 7 días.

- Fosfomicina $3 \mathrm{mg}$ única dosis.

Como alternativas:

- Cefalexina 500 mg cada 6 horas por 3 días o equivalente.

- Trimetoprim Sulfametoxazol (TMP-SMX) $160 / 800 \mathrm{mg}$ cada 12 horas por 3 días (en caso de que la resistencia local sea menor al 20\%).

No hay datos suficientes para recomendar otros antimicrobianos, a menos que se usen datos de la prevalencia de la resistencia bacteriana local. La amoxicilinaclavulanato y cefuroxima, en regímenes de 3-7 días son posibilidades terapéuticas cuando otros agentes no pueden usarse. Las fluoroquinolonas, son muy eficaces en regímenes de 3 días, pero las tasas de resistencia en nuestra institución y en el mundo son muy altas, por lo que no deben considerarse como tratamientos de primera intención, a menos que el antibiograma soporte su uso y que no haya otra opción de tratamiento. ${ }^{57}$ En los últimos años, las entidades regulatorias tanto norteamericanas como europeas, han declarado que el uso de las quinolonas debe ser restringido por sus importantes efectos secundarios y que no deben usarse como tratamiento de las infecciones de vías urinarias bajas no complicadas, reservándose sólo cuando los antibióticos anteriormente mencionados no estén disponibles o no puedan utilizarse. ${ }^{7,58}$

Según la Sociedad Americana de Enfermedades Infecciosas (IDSA), se recomienda nitrofurantoina, TMP-SMX y fosfomicina como las 3 primeras líneas de tratamiento. ${ }^{17}$ Sin embargo, como se mencionó previamente, las tasas de resistencia de TMP-SMX
TRATAMIENTO
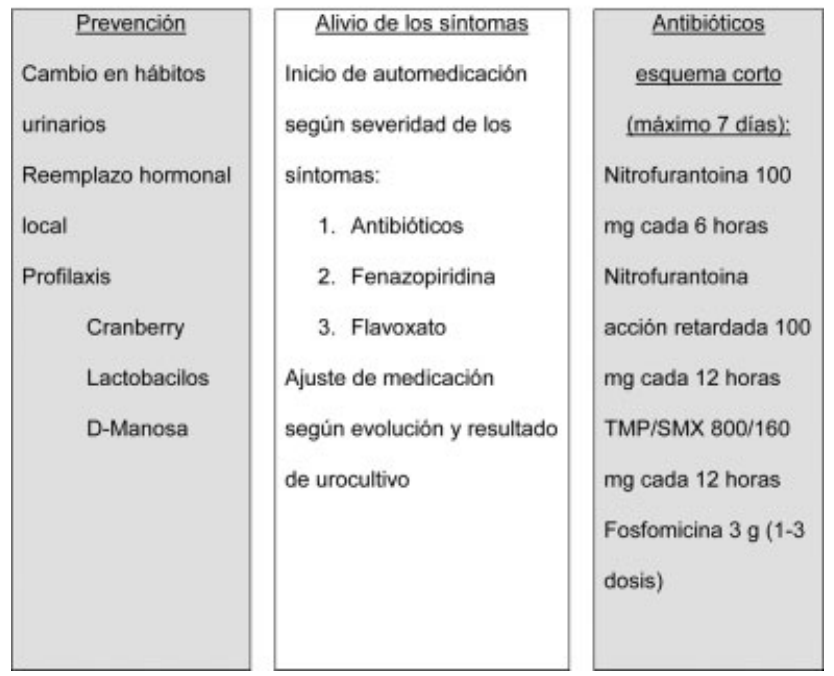

Fig. 3 Resumen prevención y tratamiento de cistitis no complicada.

en nuestro país son muy altas por lo que no recomendamos su uso. Como alternativas de segunda línea se encuentran las cefalosporinas de primera, segunda e incluso de tercera generación, sin embargo, se utilizan en casos más seleccionados.

Para el manejo de la pielonefritis no complicada en quienes se dará tratamiento ambulatorio, se administrará una dosis única de antibiótico parenteral como una cefalosporina de tercera generación y se continuará con el manejo oral ambulatorio por 7-14 días. ${ }^{17,24}$

En las comunidades con una alta tasa de E. coli productora de BLEE y resistente a fluoroquinolonas, el manejo empírico inicial recomendado es el uso de aminoglucósidos o carbapenémicos hasta que la sensibilidad del microrganismo se aclare con ayuda del antibiograma. ${ }^{29}$ Se propone Amikacina $15 \mathrm{mg} / \mathrm{kg}$ IV día o Ertapenem 1 gramo IV al día.

Mientras el antibiótico actúa, se pueden aliviar los síntomas con fenazopiridina, un analgésico urinario, a dosis de $100 \mathrm{mg}$ cada 12 horas por 3 días y/o flavoxato $200 \mathrm{mg}$ cada 8 horas por 3 días, llevando a una mejoría del dolor (ver resumen en la -Figura 3). ${ }^{59}$

\section{Resistencia antibiótica}

Las resistencias de los patógenos a los tratamientos antibióticos constituyen un gran problema en la actualidad. Eso se ve reflejado no sólo en IVU complicada, sino también en cistitis agudas no complicadas, las cuales solían ser de fácil manejo. ${ }^{60}$ El uso incorrecto de antibióticos ha dado lugar al surgimiento de patógenos con características de resistencia especiales. Actualmente la resistencia más alta de E. coli es a la ampicilina, con prevalencias que alcanzan hasta el $37,7 \%{ }^{61} \mathrm{En}$ Colombia, esa resistencia es del 51\% en Bogotá, 72\% en Popayán y 54\% en Pereira. ${ }^{44-46}$ En nuestra institución, esa resistencia se ha observado hasta en el 58\% (ver - Tabla 2). Seguido de TMP/ SMX, las resistencias de E. Coli son de aproximadamente $15,21 \%$ en Europa y Estados Unidos. Sin embargo, en Colombia alcanza tasas del $48 \%$ como es el caso de 
Tabla 2 Perfil sensibilidad E. coli en Ambulatorios y Hospitalizados 2019

\begin{tabular}{|l|l|l|l|l|}
\hline & \multicolumn{2}{|l|}{ Ambulatorios \% } & Hospitalizados \% \\
\hline Antibiótico & Resistencia & Sensibilidad & Resistencia & Sensibilidad \\
\hline BLEE & 15,2 & - & 18,5 & - \\
\hline Ampicilina & 56,6 & 42,6 & 58 & 40,3 \\
\hline Ampicilina/Sulbactam & 25,9 & 52,4 & 31,1 & 49,6 \\
\hline Ceftazidima & 16,2 & 83,7 & 21 & 79 \\
\hline Ceftriaxona & 16,1 & 83,9 & 21 & 79 \\
\hline Cefotaxima & 16,2 & 83,8 & 21 & 79 \\
\hline Cefepima & 16,1 & 83,9 & 21 & 79 \\
\hline Ertapenem & 0 & 100 & 1,7 & 98,3 \\
\hline Meropenem & 0,1 & 99,9 & 1,7 & 98,3 \\
\hline Amikacina & 0 & 100 & 0 & 100 \\
\hline Gentamicina & 12,2 & 87,5 & 7,6 & 91,6 \\
\hline Ciprofloxacina & 34,9 & 64,9 & 38,7 & 60,5 \\
\hline Norfloxacina & 34 & 64,9 & 36,4 & 61,9 \\
\hline TMP/SMX & 40,8 & 59,2 & 48,7 & 51,3 \\
\hline Fosfomicina & 2,5 & 97,2 & 1,6 & 96,8 \\
\hline Nitrofurantoina & 1,2 & 93,7 & 4,2 & 88,2 \\
\hline
\end{tabular}

Popayán. ${ }^{2,45,60}$ En el Hospital Universitario Fundación Santa Fe de Bogotá, la resistencia a ese antibiótico es similar a la encontrada en Popayán (ver - Tabla 2). En cuanto a las fluoroquinolonas, las tasas de resistencia en Estados Unidos son cercanas al 5\%, mientras que en Colombia la resistencia llega al 31\% como se reporta con la ciprofloxacina en Bogotá. ${ }^{46,61}$ Nosotros hemos identificado una tasa de resistencia de 39\% y 35\% en pacientes hospitalizados y ambulatorios, respectivamente (ver - Tabla 2).

En cuanto a la sensibilidad de E. coli al manejo antibiótico las mayores tasas son registradas para la fosfomicina con un $98 \%$, dato que es concordante con lo encontrado en nuestra institución, y a la nitrofurantoina con un $95 \%{ }^{62}$ En Fundación Santa Fe de Bogotá se encontraron tasas de sensibilidad del $94 \%$ para pacientes ambulatorios y de un $88 \%$ para pacientes hospitalizados (-Tabla 2). Lo anterior, es sustentado con estudios en Colombia que reportan las menores tasas de resistencia para la nitrofurantoina con $1,7 \%$ en Bogotá y 6,4\% en Popayán, siendo una buena alternativa como agentes de primera línea para el tratamiento empírico. ${ }^{44,46}$ Por otro lado, hemos encontrado una sensibilidad de $E$. coli a cefalosporinas de tercera y cuarta generación que oscila entre 79\% y 84\% según gérmenes encontrados en pacientes hospitalizados $y$ ambulatorios, respectivamente. En la - Tabla 3, se encuentra el resumen de mecanismos de acción y resistencia de antibióticos más frecuentemente utilizados.

\section{Prevención y profilaxis antibiótica}

La educación al paciente es un pilar fundamental en la prevención de futuras IVU. Teniendo en cuenta la naturaleza multifactorial de las IVU, se deben identificar factores de riesgo predisponentes y plantear medidas para disminuirlos. Después de la menopausia, solo $25-30 \%$ de las mujeres tienen lactobacilos en la vagina. ${ }^{63}$ Por lo tanto, en ese grupo de pacientes, particularmente si hay IVU recurrente, es clara la indicación de tratamiento con estrógenos tópicos locales como estriol, estradiol y estrógenos conjugados. Ellos tienen un alto perfil de seguridad por su mínima absorción, aumentan el porcentaje de lactobacilo y mejoran las características de atrofia vulvovaginal que hacen parte del síndrome urogenital postmenopáusico. ${ }^{17,64,65}$ Por otro lado, las mujeres sexualmente activas que utilizan métodos anticonceptivos como espermicidas, diafragmas y dispositivos intrauterinos se podrían beneficiar de consejería de planificación familiar para evaluar otras alternativas de anticoncepción. ${ }^{10}$

Como prevención, también se encuentran productos naturales como las proantocianidinas derivadas del arándano rojo (cranberry) que inhiben la adherencia, proliferación y la colonización bacteriana en el tracto urinario de salida. Sin embargo, su evidencia es heterogénea. Experimentos clínicos aleatorizados han demostrado su eficacia por su mecanismo de acción evitando la adherencia de las bacterias al urotelio. ${ }^{17}$ Según Hisano y col., el efecto anti-adherente de las proantocianidinas está directamente relacionado con la dosis administrada, sugiriendo una dosis mínima al día de 1200 mg dividido en 2-3 tomas. ${ }^{66}$ La adherencia al consumo de tabletas de arándano en comparación con el jugo parece ser mayor. Su consumo tiene gran acogida en la población, aunque no ha demostrado ser superior que la profilaxis antibiótica y por eso tiene un grado de recomendación débil. $^{7,67}$

Hay otras alternativas como la D-manosa que es un azúcar involucrado en la glicosilación de proteínas en el cuerpo 
Tabla 3 Mecanismo de acción y resistencia ${ }^{71,72}$

\begin{tabular}{|c|c|c|c|}
\hline Antibiótico & Mecanismo de acción & Dosis & Resistencia \\
\hline $\begin{array}{l}\text { Aminoglucósidos } \\
\text { Amikacina } \\
\text { Gentamicina }\end{array}$ & $\begin{array}{l}\text { Se une a proteínas de la subunidad } 30 \mathrm{~S} \text { del } \\
\text { ribosoma, en un lugar cercano al sitio A: } \\
\text { 1. Origina un cambio en la estructura } \\
\text { tridimensional del ribosoma que altera la } \\
\text { lectura (translación) y desplazamiento } \\
\text { (translocación) del ARNm. } \\
\text { 2. Desestabiliza la pared bacteriana. } \\
\text { 3. Es concentración dependiente. }\end{array}$ & $\begin{array}{l}\text { Amikacina IM o IV } 15-20 \mathrm{mg} / \mathrm{kg} / \mathrm{día} \\
\text { Gentamicina IM o IV 5-7 mg/kg/día en } \\
1 \text { a } 2 \text { dosis }\end{array}$ & $\begin{array}{l}\text { 1. La aparición de enzimas que modifican la } \\
\text { estructura del aminoglucósido. } \\
2 \text {. Disminución de la concentración } \\
\text { intracelular del aminoglucósido por reduc- } \\
\text { ción de la permeabilidad o por efecto de una } \\
\text { bomba de expulsión activa. } \\
\text { 3. Modificación de proteínas del ribosoma }\end{array}$ \\
\hline $\begin{array}{l}\text { Cefalosporinas } \\
\text { Cefalexina } \\
\text { Cefadroxilo } \\
\text { Cefuroxima } \\
\text { Ceftriaxona }\end{array}$ & $\begin{array}{l}\text { Derivados del hongo cephalosporium } \\
\text { acremonium. } \\
\text { 1. Inhiben la síntesis de peptidoglucanos } \\
\text { de la pared bacteriana y la bacteria muere } \\
\text { por efecto osmótico o digerida por enzi- } \\
\text { mas autolíticas. } \\
\text { 2. Bloquea la actividad transpeptidasa de } \\
\text { las PBP (proteínas fijadoras de la penici- } \\
\text { lina). } \\
\text { 3. Actividad bactericida tiempo- } \\
\text { dependiente. }\end{array}$ & $\begin{array}{l}\text { Cefalexina } 500 \mathrm{mg} \text { cada } 6 \text { horas o } \\
1 \mathrm{~g} \text { cada } 12 \text { horas } \\
\text { Cefadroxilo liberación sostenida } 1 \mathrm{~g} \text { día } \\
\text { Cefuroxima } 500 \mathrm{mg} \text { cada } 8-12 \text { horas } \\
\text { Ceftriaxona } 1 \mathrm{~g} \text { día. }\end{array}$ & $\begin{array}{l}\text { 1. Modificaciones o remplazo de la proteína } \\
\text { ligada a penicilina (PBP) con disminución de la } \\
\text { afinidad por el betalactámico } 2 \text {. Disminución } \\
\text { de la permeabilidad por reducción de las } \\
\text { porinas } \\
\text { de la pared bacteriana. } \\
\text { 3. Presencia de bombas de expulsión activa } \\
\text { del antibiótico desde } \\
\text { el espacio periplasmático. 4. "Tolerancia" } \\
\text { caracterizada por la persistencia de la con- } \\
\text { centración inhibitoria mínima (CIM) junto a } \\
\text { un aumento importante } \\
\text { de la concentración bactericida mínima } \\
\text { (CBM). }\end{array}$ \\
\hline $\begin{array}{l}\text { Fosfomicina } \\
\text { (Derivada del } \\
\text { acido fosfórico) }\end{array}$ & $\begin{array}{l}\text { Inhibe de forma competitiva la enzima } \\
\text { enolpiruvato transferasa MurA que inter- } \\
\text { viene en la síntesis de N-acetilmurámico } \\
\text { (componente del } \\
\text { peptidoglucano). }\end{array}$ & $\begin{array}{l}\text { Fosfomicina trometamol } 3 \mathrm{~g} \text { dosis } \\
\text { única o } 3 \mathrm{~g} \text { cada } 3 \text { días por } 3 \text { dosis. }\end{array}$ & $\begin{array}{l}\text { 1. Mutaciones cromosómicas que codifican } \\
\text { MurA con baja afinidad para fosfomicina o } \\
\text { afectan los mecanismos de transporte de } \\
\text { fosfomicina hacia el interior de la bacteria. } \\
\text { 2. Presencia de enzimas inactivantes codifi- } \\
\text { cadas por plásmidos }\end{array}$ \\
\hline Nitrofurantoina & $\begin{array}{l}\text { Bloquea la síntesis proteica en el ribo- } \\
\text { soma, rompe las cadenas de ADN y blo- } \\
\text { quea la actividad de la acetil-coenzima A. } \\
\text {. }\end{array}$ & $\begin{array}{l}50-100 \mathrm{mg} \text { cada } 6-8 \text { horas por } 7 \text { días o } \\
\text { cada } 12 \text { horas si es de liberación } \\
\text { prolongada }\end{array}$ & $\begin{array}{l}\text { La aparición de resistencias durante el trata- } \\
\text { miento es muy rara probablemente debido a } \\
\text { sus varios mecanismos de acción. }\end{array}$ \\
\hline $\begin{array}{l}\text { Quinolonas } \\
\text { Ciprofloxacina } \\
\text { Norfloxacina } \\
\text { Levofloxacina }\end{array}$ & $\begin{array}{l}\text { Bloquean la actividad de la ADN-girasa } \\
\text { (topoisomerasa II) en gram negativos y de } \\
\text { la topoisomerasa IV en gram positivos. }\end{array}$ & $\begin{array}{l}\text { Ciprofloxacina } \\
500-1000 \mathrm{mg} \text { cada } 12 \text { horas o } \\
1000 \mathrm{mg} \text { día } \\
\text { Norfloxacina } 400 \mathrm{mg} \text { cada } 12 \text { horas } \\
\text { Levofloxacina } 500-750 \mathrm{mg} \text { día. }\end{array}$ & $\begin{array}{l}\text { 1. Mutaciones cromosómicas en los genes } \\
\text { que codifican la topoisomerasa Il y IV o ADN- } \\
\text { girasa. } \\
\text { 2. Por sustitución de ciertos aminoácidos en } \\
\text { su posición de la superficie de la enzima } \\
\text { disminuye la afinidad por las quinolonas. } \\
\text { 3. Se necesitan varias mutaciones para que se } \\
\text { produzca resistencia } \\
\text { de importancia clínica. } \\
\text { 4. La resistencia es cruzada entre todas las } \\
\text { quinolonas. }\end{array}$ \\
\hline $\begin{array}{l}\text { Trimetoprim } \\
\text { Sulfametoxazol }\end{array}$ & $\begin{array}{l}\text { El trimetoprim inhibe la dihidrofolato- } \\
\text { reductasa bacteriana. La síntesis de ácido } \\
\text { fólico se bloquea en un paso previo al de } \\
\text { actuación de las sulfonamidas. } \\
\text { Sulfametoxazol hace parte del grupo de } \\
\text { sulfonamidas, inhibidor competitivo del } \\
\text { ácido paraaminobenzoico (PABA) } \\
\text { disminuyendo la síntesis de ácido fólico, } \\
\text { ácidos nucleícos y proteínas bacterianas. } \\
\text { Tienen efecto bacteriostático. } \\
\text { Los dos tienen acción sinérgica. }\end{array}$ & $160 \mathrm{mg} / 800 \mathrm{mg}$ cada 12 horas & $\begin{array}{l}\text { La resistencia del trimetoprim está mediada } \\
\text { por plásmidos que codifican la producción de } \\
\text { una dihidrofolato-reductasa dotada de menor } \\
\text { afinidad por el antibiótico. También se puede } \\
\text { deber con menor frecuencia, a la disminución } \\
\text { de la permeabilidad o sobreproducción de } \\
\text { dihidrofolato-reductasa. } \\
\text { La resistencia de sulfametoxazol se debe a la } \\
\text { mutación cromosómica o por transmisión de } \\
\text { plásmidos, que determinan una sobrepro- } \\
\text { ducción de PABA, una disminución de la } \\
\text { permeabilidad } \\
\text { de la bacteria para la sulfonamida y/o, con } \\
\text { mayor frecuencia, una alteración de la } \\
\text { enzima. }\end{array}$ \\
\hline
\end{tabular}

humano. ${ }^{68}$ Algunas teorías mencionan que su papel en la prevención de las IVU se basa en la alteración de la adherencia bacteriana a las células uroepiteliales. ${ }^{68}$ Aunque los estudios muestran que es bien tolerado y que podría ser una alternativa para reducir las recurrencias, la evidencia es escasa para hacer una recomendación contundente. ${ }^{68}$ Adicionalmente, el uso de probióticos como la terapia con lactobacilos vaginales con el fin de mejorar el crecimiento de la flora vaginal normal y prevenir la colonización por uropatógenos, ha demostrado resultados contradictorios en los diferentes estudios, por lo que tiene una recomendación débil. ${ }^{63,69}$ Por último, el consumo de vitamina $\mathrm{C}$ no tiene evidencia consistente $\mathrm{y}$ por lo tanto no se recomienda. ${ }^{63}$

Otras opciones de tratamiento diferentes al manejo antibiótico se han popularizado. Pero pocas de ellas cuentan con evidencia fuerte en la literatura. A pesar de ello, los estimulantes de la respuesta inmunológica del huésped, como el inmunoestimulante OM-89 compuesto por extractos proteicos liofilizados de 18 cepas de $E$. coli 
Tabla 4 Dosis de antibiótico profiláctico ${ }^{17}$

\begin{tabular}{|c|c|}
\hline \multicolumn{2}{|c|}{ Profilaxis continua } \\
\hline Nitrofurantoina & 50-100 mg al día. \\
\hline Cefalexina & 250 mg al día. \\
\hline Fosfomicina & $3 g$ cada 10 días. \\
\hline \multicolumn{2}{|c|}{ Profilaxis intermitente } \\
\hline Nitrofurantoina & $\begin{array}{l}50-100 \mathrm{mg} \text { dosis única. } \\
\text { Especialmente poscoito. }\end{array}$ \\
\hline Cefalexina & $\begin{array}{l}250 \mathrm{mg} \text { dosis única. } \\
\text { Especialmente poscoito. }\end{array}$ \\
\hline
\end{tabular}

causantes de IVU, han demostrado disminución de hasta un $33 \%$ de las recurrencias, ayudando así a 1 de cada 5 mujeres con periodos de latencia de hasta 6 meses. ${ }^{35}$ Otras vacunas disponibles en el mercado tampoco son recomendadas de manera rutinaria por la heterogeneidad de evidencia en los estudios.

Los factores comportamentales, los hábitos urinarios y la baja ingesta de líquidos se asocian a síntomas irritativos bajos e IVU recurrente, por lo tanto, es indispensable concientizar a las pacientes de esas estrategias de prevención. ${ }^{7}$ Es por eso, que se recomienda una ingesta de líquidos de al menos 2-3 litros al día, manejo del estreñimiento con dieta o medicamentos según sea el caso y buenos hábitos miccionales que incluyen: aumento en la frecuencia miccional por horario cada 2-3 horas, micción pre y poscoito, y una adecuada posición durante la micción que favorezca la relajación del piso pélvico llevando a un vaciamiento vesical óptimo. ${ }^{10,70}$ Todas esas recomendaciones que tienen sentido lógico, desafortunadamente no han podido ser demostradas como eficaces en realmente prevenir la aparición de episodios recurrentes de infección urinaria. ${ }^{21}$

Por último, en IVU recurrentes se recomienda profilaxis antibiótica con una duración no mayor a 12 meses teniendo en cuenta los siguientes esquemas (ver - Tabla 4):

1. Continua durante 3-6 meses: disminuye la recurrencia, carga bacteriana y sintomatología. No se recomienda el uso de cefalosporinas ni fluoroquinolonas porque aumentan las tasas de resistencia. Se recomienda como esquema de tratamiento nitrofurantoina $50-100 \mathrm{mg}$ cada 24 horas por vía oral, pero se asocia con síntomas del tracto gastrointestinal y fibrosis pulmonar. ${ }^{17}$

2. Poscoito/Intermitente: cuando se logra determinar que la causa de las recurrencias de las infecciones se asocia a la actividad sexual, esas pacientes se benefician de recibir dosis única de nitrofurantoina, cefalexina o fosfomicina poscoito. $^{17}$

3. Autotratamiento: según la severidad de los síntomas, iniciar con analgésico urinario o antiinflamatorio no esteroideo, acompañado de abundantes líquidos y de acuerdo con la evolución, iniciar o no antibiótico indicado previamente por su médico. Sin duda, es el esquema más debatido por su asociación a altas tasas de toxicidad y al aumento de resistencia bacteriana, y sin olvidar que algunas cistitis no se deben a procesos infecciosos.

\section{Conclusiones}

La infección urinaria sigue siendo una de las principales causas de consulta en servicios de urgencias y consulta prioritaria. La identificación de potenciales factores de riesgo modificables es útil, así como una adecuada elección del esquema antibiótico ajustado a las resistencias locales en cada sitio. Un plan de prevención claro modificando estilos de vida y hábitos tiene un impacto a largo plazo en la recurrencia de la infección.

Conflicto de Intereses

Los autores declaran no tener ningún conflicto de intereses.

\section{Referencias}

1 Tandogdu Z, Wagenlehner FME. Global epidemiology of urinary tract infections. Curr Opin Infect Dis 2016;29(01):73-79. Doi: 10.1097/QCO.0000000000000228

2 Hooton TM. Clinical practice. Uncomplicated urinary tract infection N Engl J Med 2012;366(11):1028-1037. Doi: 10.1056/ NEJMcp1104429

3 Prada G, Plata M. GUIA DE PRACTICA CLINICA DE INFECCION URINARIA. 2016

4 Foxman B, Brown P. Epidemiology of urinary tract infections: transmission and risk factors, incidence, and costs. Infect Dis Clin North Am 2003;17(02):227-241. Doi: 10.1016/S0891-5520(03) 00005-9

5 Kaye KS, Pogue JM. Infections Caused by Resistant Gram-Negative Bacteria: Epidemiology and Management. Pharmacotherapy 2015;35(10):949-962. Doi: 10.1002/phar.1636

6 Gupta K, Trautner BW. Urinary Tract Infection, Pyelonephritis, and Prostatitis. In: Harrison's Principles of Internal Medicine. 20th ed. New York: McGrar-Hill Education; 2018http:// accessmedicine.mhmedical.com/content.aspx?aid=1159153646

7 Bonkat G, Bartoletti R, Bruyère F, et al. EAU Guidelines on Urological Infections. In: EAU Guidelines. presented. Arnhem: EAU Guidelines Office; 2020https://uroweb.org/guideline/urological-infections/

8 File TM. Highlights from international clinical practice guidelines for the treatment of acute uncomplicated cystitis and pyelonephritis in women: A 2010 update by the infectious diseases society of America and the european society for microbiology and infectious. Infect Dis Clin Pract 2011;19(04): 282-283. Doi: 10.1097/IPC.0b013e3182231994

9 Dason S, Dason JT, Kapoor A. Guidelines for the diagnosis and management of recurrent urinary tract infection in women. Can Urol Assoc J 2011;5(05):316-322. Doi: 10.5489/cuaj.11214

10 Hooton TM. Recurrent urinary tract infections in non-pregnant adult women. S Afr Fam Pract 2009;51(06):467-470. Doi: $10.1080 / 20786204.2009 .10873905$

11 Cai T, Koves B, Bjerklund TE. Asymptomatic bacteriuria, to screen or not to screen - and when to treat? 2017:107-111. Doi: 10.1097/MOU.0000000000000368

12 Grigoryan L, Trautner BW, Gupta K. Diagnosis and management of urinary tract infections in the outpatient setting: a review. JAMA 2014;312(16):1677-1684. Doi: 10.1001/jama.2014.12842

13 Rhodes A, Evans LE, Alhazzani W, et al. Surviving Sepsis Campaign: International Guidelines for Management of Sepsis and Septic Shock. Vol 45. Springer Berlin Heidelberg 2016;2017; Doi: 10.1097/CCM.0000000000002255 
14 Wagenlehner FME, Pilatz A, Weidner W, Naber KG. Urosepsis: Overview of the Diagnostic and Treatment Challenges. Microbiol Spectr 2015;3(05):1-18. Doi: 10.1128/microbiolspec.uti-0003-2012

15 Wagenlehner FME, Tandogdu Z. An update on classification and management of urosepsis. 2017:133-137. Doi: 10.1097/MOU.0000 000000000364

16 Geerlings SE, Bartoletti R, Pilatz A, et al. Management of Urosepsis in 2018;2018(05):5-9. Doi: 10.1016/j.euf.2018.11.003

17 Anger J, Lee U, Ackerman AL, et al. Infection / Inflammation Recurrent Uncomplicated Urinary Tract Infections in Women. 2019;202(August):282-289

18 Orrego-Marín CP, Henao-Mejía CP, Cardona-Arias JA. Prevalencia de infección urinaria, uropatógenos y perfil de susceptibilidad antimicrobiana. Acta Med Colomb 2014;39:352-358http://www. scielo.org.co/pdf/amc/v39n4/v39n4a08.pdf

19 Alviz-Amador A, Gamero-Tafur K, Caraballo-Marimon R, GameroTafur J. Prevalencia de infección del tracto urinario, uropatógenos y perfil de susceptibilidad en un hospital de Cartagena, Colombia. 2016. Rev Fac Med (Caracas) 2018;66(03):313-317. Doi: 10.15446/revfacmed.v66n3.62601

20 Foxman B, Geiger AM, Palin K, Gillespie B, Koopman JS. First-time urinary tract infection and sexual behavior. Epidemiology 1995; 6 (02):162-168. Doi: 10.1097/00001648-199503000-00013

21 Scholes D, Hooton TM, Roberts PL, Stapleton AE, Gupta K, Stamm WE. Risk factors for recurrent urinary tract infection in young women. J Infect Dis 2000;182(04):1177-1182. Doi: 10.1086/315827

22 Raz R, Gennesin Y, Wasser J, et al. Recurrent Urinary Tract Infections in Postmenopausal Women. Clin Infect Dis 2000; 30:152.156. Doi: $10.1086 / 313596$

23 Rosen DA, Hooton TM, Stamm WE, Humphrey PA, Hultgren SJ. Detection of intracellular bacterial communities in human urinary tract infection. PLoS Med 2007;4(12):e329. Doi: 10.1371/journal. pmed.0040329

24 Flores-Mireles AL, Walker JN, Caparon M, Hultgren SJ. Urinary tract infections: epidemiology, mechanisms of infection and treatment options. Nat Rev Microbiol 2015;13(05):269-284

25 Hung C, Bouckaert J, Hung D, et al. Structural basis of tropism of Escherichia coli to the bladder during urinary tract infection. 2002; 44:903-915

26 Duell BL, Carey AJ, Tan CK, et al. Innate transcriptional networks activated in bladder in response to uropathogenic Escherichia coli drive diverse biological pathways and rapid synthesis of IL-10 for defense against bacterial urinary tract infection. J Immunol 2012; 188(02):781-792. Doi: 10.4049/jimmunol.1101231

27 Mysorekar IU, Hultgren SJ. Mechanisms of uropathogenic Escherichia coli persistence and eradication from the urinary tract. 2006;103(38):

28 Hannan TJ, Roberts PL, Riehl TE, et al. Inhibition of Cyclooxygenase-2 Prevents Chronic and Recurrent Cystitis. EBioMedicine 2014;1(01): 46-57. Doi: 10.1016/j.ebiom.2014.10.011

29 Pak J, Pu Y, Zhang ZT, Hasty DL, Wu XR. Tamm-Horsfall protein binds to type 1 fimbriated Escherichia coli and prevents E. coli from binding to uroplakin Ia and Ib receptors. J Biol Chem 2001; 276(13):9924-9930. Doi: 10.1074/jbc.M008610200

30 Waksman G, Hultgren SJ. Structural biology of the chaperoneusher pathway of pilus biogenesis. Nat Rev Microbiol 2009;7(11): 765-774. Doi: $10.1038 /$ nrmicro2220

31 Vauré C, Liu Y. A comparative review of toll-like receptor 4 expression and functionality in different animal species. Front Immunol 2014;5(316):316. Doi: 10.3389/fimmu.2014. 00316

32 Robinson AE, Lowe JE, Koh E, Henderson JP. Uropathogenic enterobacteria use the yersiniabactin metallophore system to acquire nickel. 2018;293(19):14953-14961. Doi: 10.1074/jbc.RA1 18.004483

33 Su Q, Guan T, He Y, Lv H. Siderophore biosynthesis governs the virulence of uropathogenic Escherichia coli by coordinately modulating the differential metabolism. J Proteome Res 2016; 15(04):1323-1332. Doi: 10.1021/acs.jproteome.6b00061
34 Garcia TA, Ventura CL, Smith MA, Merrell DS, O'Brien AD. Cytotoxic necrotizing factor 1 and hemolysin from uropathogenic Escherichia coli elicit different host responses in the murine bladder. Infect Immun 2013;81(01):99-109. Doi: 10.1128/IAI.00605-12

35 Goller CC, Seed PC. Revisiting the Escherichia coli polysaccharide capsule as a virulence factor during urinary tract infection: contribution to intracellular biofilm development. Virulence 2010;1(04):333-337. Doi: 10.1126/science.1084550

36 Paterson DL. Resistance in gram-negative bacteria: enterobacteriaceae. Am J Med 2006;119(06, Suppl 1):S20-S28, discussion S62-S70 . Doi: 10.1016/j.amjmed.2006.03.013

37 Gupta K, Bhadelia N. Management of urinary tract infections from multidrug-resistant organisms. Infect Dis Clin North Am 2014;28 (01):49-59. Doi: 10.1016/j.idc.2013.10.002

38 Huang B, Fettweis JM, Brooks JP, Jefferson KK, Buck GA. The changing landscape of the vaginal microbiome. Clin Lab Med 2014;34(04):747-761. Doi: 10.1016/j.cll.2014.08.006

39 Swidsinski A, Loening-Baucke V, Mendling W, Swidsinski S. Positive effects of local therapy with a vaginal lactic acid gel on dysuria and $E$. coli bacteriuria question our current views on recurrent cystitis. Arch Gynecol Obstet 2012;285(06):1619-1625. Doi: 10.1007/ s00404-011-2196-z

40 Zárate G, Nader-Macias ME. Influence of probiotic vaginal lactobacilli on in vitro adhesion of urogenital pathogens to vaginal epithelial cells. Lett Appl Microbiol 2006;43(02):174-180. Doi: 10.1111/j.1472-765X.2006.01934.X

41 O'Hanlon DE, Moench TR, Cone RA. Vaginal pH and microbicidal lactic acid when lactobacilli dominate the microbiota. PLoS One 2013;8(11):e80074. Doi: 10.1371/journal.pone.0080074

42 Grabe M, Bjeklund T, Botto H, Naber G, Tenke P, Wangenlehner F. Guia clínica sobre las infecciones urológicas. Eur Assoc Urol 2010: 1-136http://www.aeu.es/UserFiles/17GUIA_CLINICA_SOBRE_LAS_INFECCIONES_UROLOGICAS.pdf

43 Ronald A. The etiology of urinary tract infection: traditional and emerging pathogens. Dis Mon 2003;49(02):71-82. Doi: 10.1016/ S0011-5029(03)90001-0

44 Caicedo PS, Martinez T, Meneses E, et al. Etiologia y resistencia bacteriana en infección de vías urinarias en el hospital universitario san jose de popayan, colombia entre enero y diciembre de 2008. Urol Colomb 2009;13(03):45-52http://www.urologiacolombiana.com/ userfiles/file/6 - ETILOGIA Y RESISTENCIA BACTERIANA.pdf

45 Machado-Alba JE, Murillo-Muñoz MM. Evaluación de sensibilidad antibiótica en urocultivos de pacientes en primer nivel de atención en salud de Pereira. Rev Salud Publica (Bogota) 2012; 14(04):710-719http://www.scielo.org.co/scielo.php? pid=S0124-00642012000400014\&script=sci_abstract $\&$ tlng=es

46 Gómez C, Plata M, Sejnaui J, Rico C, González S. Resistencia de la E. coli en urocultivos de pacientes con sospecha de infección urinaria intr y extra-hospitalaria en la Fundación Santa Fe de Bogotá. Urol Colomb 2009;18(01):8

47 Campuzano G, Arbeláez M. El Uroanálisis: Un gran aliado del médico. Rev Urol Colomb 2007;XVI(01):67-92

48 Moyes RB, Reynolds J, Breakwell DP. Differential staining of bacteria: gram stain. Curr Protoc Microbiol 2009;3(Appendix, SUPPL. 15)3C. Doi: 10.1002/9780471729259.mca03cs15

49 Wein AJ, Kolon TF, Partin AW. Campbell-Walsh-Wein Urology Twelfth Edition. 1141

50 Microbitos G. Pruebas bioquímicas primarias: Tinción de GRAM, prueba de catalasa, prueba de oxidasa, prueba de $\mathrm{O} / \mathrm{F}$ y motilidad. http://microbitosblog.com/2011/09/27/pruebas-bioquimicasprimarias/. Published 2015

51 Tille PM. Bailey \& Scott's Diagnostic Microbiology. 14th ed. Elsevier; 2017

52 Cortes JA, Perdomo D, Morales R, et al. Guía de práctica clínica sobre diagnóstico y tratamiento de infección de vías urinarias no complicada en mujeres adquirida en la comunidad. 2015;63(04): 565-581 
53 Falagas ME, Kotsantis IK, Vouloumanou EK, Rafailidis PI. Antibiotics versus placebo in the treatment of women with uncomplicated cystitis: a meta-analysis of randomized controlled trials. J Infect 2009;58(02):91-102. Doi: 10.1016/j.jinf.2008.12.009

54 Foxman B. The epidemiology of urinary tract infection. Nat Rev Urol 2010;7(12):653-660. Doi: 10.1038/nrurol.2010.190

55 Gilbert DN, Chambers HF, Saag MS, et al. The Sanford Guide To Antimicrobial Therapy 2020. 50th ed. Sperryville: Antimicrobial Therapy, INC; 2020

56 Bassetti M, Giacobbe DR, Giamarellou H, et al; Critically Ill Patients Study Group of the European Society of Clinical Microbiology and Infectious Disease (ESCMID); Hellenic Society of Chemotherapy (HSC) and Società Italiana di Terapia Antinfettiva (SITA). Management of KPC-producing Klebsiella pneumoniae infections. Clin Microbiol Infect 2018;24(02):133-144. Doi: 10.1016/j. cmi.2017.08.030

57 Gupta K, Hooton TM, Naber KG, et al; Infectious Diseases Society of America European Society for Microbiology and Infectious Diseases. International clinical practice guidelines for the treatment of acute uncomplicated cystitis and pyelonephritis in women: A 2010 update by the Infectious Diseases Society of America and the European Society for Microbiology and Infectious Diseases. Clin Infect Dis 2011;52(05):e103-e120. Doi: 10.1093/cid/ciq257

58 Anger J, Lee U, Ackerman AL, Chughtai B, Clemens JQ, Hickling D. American Urological Association (AUA) / Canadian Urological Association (CUA) / Society of Urodynamics, Female Pelvic Medicine \& Urogenital Reconstruction (SUFU) Recurrent Uncomplicated Urinary Tract Infections in Women: AUA / CUA / SUFU Guideline R. 2019;(April):1-36

59 Jung $C$, Brubaker L. The etiology and management of recurrent urinary tract infections in postmenopausal women. Climacteric 2019;22(03):242-249. Doi: 10.1080/13697137.2018.1551871

60 Gupta K. Emerging antibiotic resistance in urinary tract pathogens. Infect Dis Clin North Am 2003;17(02):243-259. Doi: 10.1016/S0891-5520(03)00006-0

61 Zhanel GG, Hisanaga TL, Laing NM, et al; NAUTICA Group. Antibiotic resistance in Escherichia coli outpatient urinary isolates: final results from the North American Urinary Tract Infection Collaborative Alliance (NAUTICA). Int J Antimicrob Agents 2006; 27(06):468-475. Doi: 10.1016/j.jijantimicag.2006.02.009

62 Naber KG, Schito G, Botto H, Palou J, Mazzei T. Surveillance study in Europe and Brazil on clinical aspects and Antimicrobial Resistance Epidemiology in Females with Cystitis (ARESC): implications for empiric therapy. Eur Urol 2008;54(05): 1164-1175. Doi: 10.1016/j.eururo.2008.05.010

63 Beerepoot M, Geerlings SE. Non-Antibiotic Prophylaxis for Urinary Tract Infections. 2016. Doi: 10.3390/pathogens5020036

64 Nappi RE, Martini E, Cucinella L, et al. Addressing Vulvovaginal Atrophy (VVA)/Genitourinary Syndrome of Menopause (GSM) for Healthy Aging in Women. Front Endocrinol (Lausanne) 2019;10 (August):561. Doi: 10.3389/fendo.2019.00561

65 Portman DJ, Gass MLS, Kingsberg S, et al; Vulvovaginal Atrophy Terminology Consensus Conference Panel. Genitourinary syndrome of menopause: new terminology for vulvovaginal atrophy from the International Society for the Study of Women's Sexual Health and the North American Menopause Society. Menopause 2014;21(10):1063-1068. Doi: 10.1097/ gme.0000000000000329

66 Hisano M, Bruschini H, Nicodemo AC, Srougi M. Cranberries and lower urinary tract infection prevention. Clinics (São Paulo) 2012; 67(06):661-668. Doi: 10.6061/clinics/2012(06)18

67 Ashraf MS, Gaur S, Bushen OY, et al; Infection Advisory SubCommittee for AMDA-The Society of Post-Acute and LongTerm Care Medicine. Diagnosis, Treatment, and Prevention of Urinary Tract Infections in Post-Acute and Long-Term Care Settings: A Consensus Statement From AMDA's Infection Advisory Subcommittee. J Am Med Dir Assoc 2020;21(01): 12-24.e2. Doi: 10.1016/j.jamda.2019.11.004

68 Sihra N, Goodman A, Zakri R, Sahai A, Malde S. Nonantibiotic prevention and management of recurrent urinary tract infection. Nat Rev Urol 2018;15(12):750-776. Doi: 10.1038/s41585-0180106-x

69 Valdevenito JP. Infección urinaria recurrente en la mujer. Infectología al día 2008;25(04):268-276

70 Sotomayor De Zavaleta M, Ponce De León Garduño A, Guzmán Esquivel J, et al. Recomendaciones de expertos mexicanos en el tratamiento de las infecciones del tracto urinario en pacientes adultos, embarazadas y niños. 2015;75(02):1-46

71 Mensa J, Gatell J, García-Sánchez J, Letang E, López-Suñé E, Marco F. Guía de Terapéutica Antimicrobiana 2018. Antares E, ed. Barcelona2018

72 MacDougall C. Section VII: Chemotherapy of Infectious Diseases. In: Brunton LL, Hilal-Dandan R, Knollman BC, eds. Goodman \& Gilman's: The Pharmacological Basis of Therapeutics. 13th ed. New York: McGraw-Hill Education; 2020 